\title{
Efectodel uso del suelo sobre rizobacterias fosfatosolubizadoras y diazotroficas en el distrito de riego del río Zulia, Norte de Santander (Colombia)
}

\author{
Ronal Fernando Cañón ${ }^{1}$ | Vanessa Paola Prato ${ }^{2}$ | María Alessandra Alterio Sabino ${ }^{3}$ | Diana María Cárdenas Caro ${ }^{4}$
}

Recibido:

21 de agosto de 2008

Aceptado:

14 de diciembre de 2009
Plan de estudios de Ingeniería Biotecnológica - Semillero de Investigación SIBAA, UFPS. ronaldfer11@hotmail.com

${ }^{2}$ Plan de estudios de Microbiología, Universidad de Pamplona

${ }^{3}$ Ing. Agrónomo - Profesional especializado del Instituto Colombiano Agropecuario, ICA

${ }^{4}$ Ing. de Prod. Biotecnológica, M Sc. Docente Depto. Biología, UFPS. Coordinadora del Semillero de Investigación SIBAA - Grupo de Investigaciones Ambiente y Vida. Trabajo presentado en la $\mathrm{V}$ semana de ciencia, tecnología e innovación - UFPS

\section{Resumen}

Se cuantificaron poblaciones de rizobacterias diazotróficas y fosfatosolubilizadoras con el fin de determinar el efecto del uso del suelo durante diferentes períodos de intervención con cultivo de arroz en tres zonas agroecológicas del Distrito de Riego del Zulia. Los resultados mostraron que el manejo del cultivo de arroz en las diferentes zonas estudiadas influyó significativamente sobre la población de microorganismos en todos los medios de cultivo utilizados, excepto en el medio semisólido JMV. La población de estos géneros como Azospirillum spp., Azotobacter spp., Beijerinckia spp., se vio influenciada por la fertilidad de los suelos en las diferentes zonas, como resultado de la liberación de exudados de las raíces, como se observó en la zona de Buena Esperanza y Restauración con respecto a Limoncito, donde se encuentran bajas condiciones de materia orgánica y de elementos nutricionales esenciales. Además, se observó que las mayores poblaciones de microorganismos diazotróficos y fosfatosolubilizadores se encontraron en suelos rizosféricos cultivados durante menos de dos años y entre dos y diez años, lo cual evidencia el impacto sobre la microbiota por el manejo de agricultura convencional en estas zonas. Se obtuvieron 28 aislamientos de rizobacterias diazotróficas endófitas, asociativas, de vida libre y fosfatosolubilizadoras según sus características macroscópicas en agar Batata, JMV, Ashby y nutritivo a partir de los análisis de población en las zonas de Buena Esperanza, Restauración y Limoncito. Estos aislamientos se purificaron y conservaron en solución salina estéril $(0,85 \% \mathrm{NaCl})$ a $4^{\circ} \mathrm{C}$ en el Laboratorio de Microbiología del Instituto Colombiano Agropecuario, ICA para posteriores estudios del potencial biofertilizante en suelos arroceros del departamento.

Palabras Clave: Rizobacterias, diazotróficas, fosfatosolubilizadoras, fijadoras de nitrógeno. 


\section{Efecto del uso del suelo sobre rizobacterias fosfatosolubizadoras y diazotroficas en el distrito de riego del río Zulia, Norte de Santander (Colombia)}

\section{Abstract}

It was quantified the population of diazotrophic and phosphate solubilizer bacteria with the aim of determine the effect of the use of soils during different periods of intervention with culture of rice in three agro-ecological zones of the District of Irrigation of the Zulia river. The results showed that the management of the culture of rice in the different studied zones significantly influenced the population of microorganisms in all the studied culture media, excepting the semi-solid culture media JMV. The populations of the genera Azospirillum spp., Azotobacter spp., Beijerinckia spp., were influenced by the fertility of the soils in the zones of Buena Esperanza and Restauración compared with Limoncito, where the quantities of organic matter and nutritional escential elements were lower. It were obtained 28 isolations of entophytic, associative, free-living diazotrophic and phosphate solubilizer rhizobacteria according with their macroscopic characteristics in the culture media Batata, JMV, Ashby and nutritive, from the analysis of the population in the zones of Buena Esperanza, Restauración and Limoncito. These isolations were purified and preserved in sterilized saline solution $(0.85 \% \mathrm{NaCl})$ at $4^{\circ} \mathrm{C}$ in the Laboratory of Microbiology of the Colombian Agricultural Institute, ICA, with the purpose to be used in subsequent studies about their potential as biofertilizers in rice cultured soils of the department.

Keywords: Rhizobacteria, diazotrophic, phosphate solubilizer.

\section{Introducción}

L a siembra continua de arroz durante los últimos 40 años en el Distrito de Riego del Río Zulia y los alrededores, junto con los sistemas de preparación del suelo, han generado cambios en las propiedades físicoquímicas y biológicas de los suelos arroceros de esta región. Resultados de estudios de suelos en diferentes zonas agroecológicas productoras de arroz de la región, de los municipios de Cúcuta, el Zulia, Tibú, Villa del Rosario y San Cayetano, demostraron que más del $80 \%$ de los suelos estudiados, registran un avanzado estado de degradación de las propiedades físicas, químicas y biológicas como consecuencia de las excesivas labores de preparación del suelo y la siembra en monocultivo de arroz. Además fue evidente el deterioro estructural debido a la pérdida continua de la materia orgánica del horizonte superficial que ha conllevado a la reducción de la actividad biológica, presentándose también una fuerte acidificación de los suelos y alta concentraciones de elementos tóxicos como el hierro y el manganeso (Blanco, 1999).

El modelo de agricultura convencional que se ha practicado en el sector arrocero ha alterado el equilibrio de esas propiedades fisicoquímicas y biológicas del suelo mediante el uso continuado de fertilizantes sintéticos y la aplicación generalizada de agroquímicos para el control de arvenses, insectos y enfermedades, generando impacto ambiental negativo, manifestándose no sólo en los altos costos de producción y baja rentabilidad de los cultivos si no además en la disminución de las poblaciones de organismos benéficos y microorganismos del suelo que facilitan la disponibilidad de nutrientes especialmente del fósforo y nitrógeno en las plantas de arroz (Santos et al., 2006). 
Por lo tanto, una alternativa para recuperar el componente biótico de los suelos y lograr una producción sostenible en el cultivo de arroz ha sido la aplicación de rizobacterias promotoras del crecimiento llamadas PGPR (Plant growth promoting rizobacterias) que colonizan las raíces y promueven el crecimiento de las plantas, bien directamente mediante la secreción de hormonas o indirectamente inhibiendo organismos fitopatógenos $\mathrm{O}$ mejorando la asimilación de las fuentes minerales.

Si se tiene en cuenta que el suelo es habitado por millones de organismos que interactúan con el medio abiótico para proporcionar una buena disponibilidad de nutrientes a los cultivos y por ende protegerlos contra plagas y enfermedades, que desencadenan en valores de productividad, se desarrolló la cuantificación y aislamientodemicroorganismossolubilizadores de fosfatos y bacterias diazotróficas, con el fin de determinar el efecto del uso del suelo sobre estos microorganismos según las prácticas agrícolas desarrolladas durante diferentes períodos de tiempo en el Distrito de Riego del río Zulia, Norte de Santander.

\section{Materiales y métodos}

Cuantificación de poblaciones de rizobacterias. Se utilizaron metodologías de recuento de rizobacterias asimbióticas fijadoras de nitrógeno y fosfatosolubilizadores con el objetivo de determinar el efecto de diferentes períodos de uso del suelo con cultivos de arroz sobre las poblaciones de estos microorganismos.

Toma de muestras. Se muestrearon suelos cultivados con arroz, mediante cuatro períodos de uso del suelo con este cultivo como son: suelos cultivados durante periodos menores a dos años, suelos cultivados durante dos a diez años, suelos cultivados por periodos mayores a diez años y suelos no rizosféricos no cultivados, en las zonas de Buena Esperanza, Restauración y Limoncito del Distrito de Riego del Río Zulia.
El muestreo se realizó en diferentes veredas por zona, tomando 5 plantas con su rizósfera en un trayecto diagonal en tres fincas que representaron tres repeticiones por cada periodo de intervención.

Cuantificación de rizobacterias Endófitas, asociativas y aeróbicas de vida libre. El suelo rizosférico se obtuvo removiendo las raíces sobre papel estéril, para retirar las partículas adyacentes a la raíz de lo cuales se realizaron diluciones seriadas hasta 10-7 en tubos con $9 \mathrm{~mL}$ de solución salina al $0.85 \%$ de $\mathrm{NaCl}$.. Una vez obtenidas las diluciones, se inocularon 0,1 mL de la dilución 10-2 hasta10-7 por triplicado en viales con $5 \mathrm{~mL}$ de medio semisólido de Nfb y JMV, para el recuento de Azospirillum spp. y Burkholderia spp., respectivamente (Döbereiner et al. 1995). Para el recuento de Azotobacter spp. y Beijerinckia spp. se utilizaron cajas Petri con agar Ashby inoculadas con todas las diluciones. Se incubaron durante 4 a 8 días hasta la formación de colonias a $32^{\circ} \mathrm{C}$.

Al cabo del período de incubación, se realizó la lectura de los viales, considerando un crecimiento positivo la formación de película subsuperficial bien estructurada, para cada dilución y repetición realizada. La interpretación se realizó según la tabla de Mc Craddy (Dobereiner et al, 1995) para la cuantificación del NMP (Número Más Probable) de rizobacterias diazotróficas endófitas y asociativas.

En el caso aeróbicas de vida libre, se realizó la lectura de las cajas teniendo en cuenta la dilución en la que pudieron contarse colonias con pigmento marrón o verde, viscosas y con abundante crecimiento para el género Azotobacter y colonias bien estructuradas, redondas, viscosas y translúcidas para el género Beijerinckia, este último pudo identificarse preliminarmente con la prueba del asa, que consistió en tomar la colonia con un asa estéril y observar su elasticidad debida a la producción de exopolisacáridos (Beckin et al., 1991). El reporte se realizó en UFC/ g de suelo. 
Efecto del uso del suelo sobre rizobacterias fosfatosolubizadoras y diazotroficas en el distrito de riego del río Zulia, Norte de Santander (Colombia)

Cuantificación de rizobacterias fosfatosolubilizadoras. A partir de las diluciones obtenidas para el recuento de rizobacteria endófitas, asociativas y aeróbicas de vida libre, se inocularon $0,1 \mathrm{~mL}$ de cada dilución por triplicado en cajas Petri con agar SRSM (Sundara, \& Sinha, 1963) y se incubaron durante 4 a 8 días hasta la formación de colonias a $32^{\circ} \mathrm{C}$.

Después del tiempode incubación, se realizó la lectura de las cajas teniendo en cuenta la dilución en la que pudieron contarse colonias amarillas con halos bien formados por la producción de ácidos orgánicos alrededor de las colonias desarrollando el viraje del indicador de $\mathrm{pH}$ (Púrpura de Bromocresol), indicando la solubilización del fosfato tricálcico presente en este agar. El reporte se realizó en UFC/ g de suelo.

Análisis estadístico. Se realizó un diseño experimental es un completamente al azar con arreglo factorial 4 (Tiempo de uso del suelo: Suelos cultivados con arroz durante menos de 2 años, Suelos cultivados con arroz durante 2 a 10 años, Suelos cultivados con arroz durante más de 10 años y Suelos no rizosféricos, no cultivados) x 3 (Zonas: Buena Esperanza, Limoncito y Restauración) para un total de 12 tratamientos y tres repeticiones cada uno, representadas en cada finca analizada por zona. Se realizó un análisis de varianza y pruebas de comparación múltiple de Duncan con 0,5\% de probabilidad, con el fin de determinar el efecto del tiempo de intervención con el cultivo de arroz sobre rizobacterias diazotróficas y fosfatosolubilizadoras, utilizando el programa estadístico SPSS 10.0 para Windows.

Aislamiento de rizobacterias endófitas y asociativas. Para el aislamiento de rizobacterias endófitas y asociativas se seleccionaron al azar réplicas de los viales empleados para estimar el NMP que presentan crecimiento positivo para la formación de película en medios semisólidos $\mathrm{NFb}$ y JMV en el recuento de población de suelo rizosférico, y se repicaron en un nuevo medio sólido de agar Batata y JMV hasta la purificación de colonias (Dobereiner et al., 1995).
Aislamiento de rizobacterias aeróbicas de vida libre. Para el aislamiento de rizobacterias aeróbicas de vida libre se seleccionaron colonias con pigmento marrón o verde, viscosas y con abundante crecimiento para el género Azotobacter spp. y colonias bien estructuradas, redondas, viscosas y translúcidas para el género Beijerinckia spp. las cuales se repicaron en un nuevo medio sólido de agar Ashby para obtener colonias aisladas.

$\begin{array}{llr}\text { Aislamiento de } & & \text { rizobacterias } \\ \end{array}$ fosfatosolubilizadoras. Se seccionaron colonias amarillas con halos bien formados, las cuales se repicaron nuevamente en un nuevo medio sólido de agar Nutritivo mediante agotamiento para obtener colonias aisladas las cuales fueron numeradas y conservadas por el método descrito anteriormente.

Conservación de cepas aisladas. Los aislamientos fueron codificados teniendo en cuenta su origen. Una vez purificadas, las colonias se suspendieron en $70 \mathrm{~mL}$ de solución salina estéril al $0,85 \%$ de $\mathrm{NaCl}$ y se inoculó $1 \mathrm{~mL}$ en viales estériles para su conservación a $4^{\circ} \mathrm{C}$ en el Laboratorio de Microbiología del Instituto Colombiano Agropecuario, ICA.

\section{Resultados y discusiones}

Efecto de la zona arrocera sobre la población de rizobacterias. El análisis estadístico mostró que las zonas estudiadas influyen estadísticamente sobre la población de microorganismos en todos los medios de cultivo utilizados, excepto en el medio semisólido JMV (Tabla 1).

La población de microorganismos en el medio semisólido NFb presentó diferencias significativas para la zona de Buena Esperanza ya que en ella se encuentran mayores niveles de fertilidad expresados en capacidad de intercambio catiónico, calcio, manganeso, con respecto a las otras dos zonas, donde no se encontraron diferencias estadísticas. 
Tabla 1. Número de células de rizobacterias en medio NFb, JMV, Asbhy y SRSM en suelos cultivados y no cultivados con arroz con respecto a la zona.

\begin{tabular}{|c|c|c|c|c|}
\hline Zona & $\begin{array}{c}\text { NFb } \\
{\text { (1) Núm. células } g^{-1}}\end{array}$ & $\begin{array}{c}\text { JMV } \\
{\text { (1) Núm. células } \mathrm{g}^{-1}}\end{array}$ & $\begin{array}{l}\text { Ashby } \\
\text { (1) UFC. } \text { g }^{-1}\end{array}$ & SRSM ${ }^{(1)}$ UFC. $g^{-1}$ \\
\hline Buena. Esperanza & $6,57 \mathrm{a}$ & $7,06 \mathrm{a}$ & $5,04 \mathrm{a}$ & $4,34 a$ \\
\hline Restauración & $5,59 \mathrm{~b}$ & $6,41 \mathrm{a}$ & $5,04 a$ & $4,59 a$ \\
\hline Limoncito & $4,91 \mathrm{~b}$ & $6,41 \mathrm{a}$ & $1,29 \mathrm{~b}$ & $1,29 \mathrm{~b}$ \\
\hline
\end{tabular}

(1) Análisis estadísticos con datos transformados en Log. Medias seguidas con la misma letra en cada medio evaluado no presentan diferencia significativa entre sí por el Test de Duncan $(\mathrm{P} \leq 0,05)$.

Este medio $\mathrm{NFb}$ ha sido utilizado para el aislamiento de las diferentes especies de Azospirillum descritas hasta la fecha. Azospirillum spp. exhibe quimiotaxis positiva hacia ácidos orgánicos, azúcares, aminoácidos y compuestos aromáticos, así como hacia exudados rizosféricos. Esto podría explicar en parte, la presencia de un mayor número de microorganismos en la zona de Buena Esperanza, ya que las plantas de arroz por las condiciones del suelo presentan un mejor desarrollo, y por lo tanto aumentan la rizodeposición en la zona rizosférica, lo que se traduce en una abundante actividad microbiana.

Sin embargo, en las zonas de Restauración y de Limoncito, donde las condiciones de fertilidad del suelo son menores (Blanco, 1999), se evidenció la presencia de microorganismos en el medio $\mathrm{NFb}$, lo que puede atribuirse a que las bacterias de este género poseen un metabolismo versátil que le permite adaptarse y establecerse en el medioambiente adverso y competitivo de la rizósfera. En condiciones desfavorables, como la limitación de nutrientes, las células de Azospirillum pueden experimentar ciertos cambios morfológicos y bioquímicos para formar estructuras similares a quistes que le permiten sobrevivir a condiciones físicas adversas (Sadasivan \& Neyra, 1987).

Pese a que en las zonas de Restauración y Limoncito no se encontraron diferencias significativas, ésta última presentó la menor población de diazotróficos en medio $\mathrm{NFb}$. El deterioro de la actividad biológica de los suelos de la zona de Limoncito, se evidencian en los bajos contenidos de materia orgánica $(2,31 \%)$, la fuerte acidificación de los suelos a causa del lavado de cationes intercambiables y las altas concentraciones de Fe y Mn, debido al monocultivo con arroz riego desde hace más de 25 años (Blanco, 1999).

Por otro lado, los diazotróficos estudiados en el medio Ashby, presentaron mayor población en las zonas de Buena Esperanza y Restauración, evidenciando nuevamente el resultado de la fertilidad de los suelos sobre la actividad microbiana en la rizósfera de plantas con mayores condiciones nutricionales. Aunque estos géneros no sean altamente dependientes de los exudados radicales, se ven favorecidos por la disponibilidad de fuentes de $\mathrm{C}$ y $\mathrm{N}$ presentes en la rizósfera, lo que permitió encontrar un aumento de la población en estas dos zonas arroceras donde que presentan altas concentraciones de calcio, lo cual favorece la actividad de Azotobacter y otros micronutrientes como $\mathrm{Mn}, \mathrm{Cu}$ y $\mathrm{Zn}$ (Blanco, 1999).

Estas mismas condiciones de fertilidad afectaron las poblaciones de solubilizadores de fósforo en las zonas estudiadas, por esta razón, el comportamiento de estos microorganismos en el medio SRSM, fue similar al observado en los diazotróficos sobre agar Ashby. La mayoría de los microorganismos solubilizadores de fosfato solubilizan complejos CaP y sólo unos pocos pueden solubilizar complejos $\mathrm{FeP}$ o AlP, y puede garantizarse su efectividad en suelos con un suplemento de roca fosfórica (Gyaneshwar et al., 2002 citado por Castilla et al., 2006) como ocurre en las diferentes zonas arroceras del Distrito de Riego del río Zulia. En la zona de Limoncito se encontraron menores poblaciones de fosfatosolubilizadores, 
diferente estadísticamente de las demás zonas en el medio SRSM, en la cual se encuentra el mayor valor de fósforo disponible (25 ppm) con respecto a las zonas de Restauración $(18 \mathrm{ppm})$ y Buena Esperanza (15 ppm), lo que hace que los microorganismos no desarrollen la actividad de solubilización ya que tienen suficiente fósforo disponible en el suelo, mientras que en las dos últimas zonas los microorganismos deben desarrollar la solubilización de fosfatos para satisfacer sus requerimientos nutricionales y así mismo, beneficiar a otros grupos microbianos no solubilizadores de fósforo y a las raíces de las plantas.

En el medio de cultivo JMV semisólido no se presentaron diferencias estadísticas significativas con respecto a las zonas estudiadas. En este medio pueden aislarse bacterias de los géneros Burkholderia, Sphingomonas, Pseudomonas y otras enterobacterias. Por esta razón, se encontró la presencia de un mayor número de diazotróficos asociados a estos géneros sin observarse influencias del manejo agronómico de cada zona. Se ha reportado la presencia de especies de Burkholderia asociadas a las raíces del arroz, como B. vietnamiensis, descubierta en asociación con raíces de arroz cultivadas en suelos vietnamienses (Gillis et al., 1995 citado por Estrada-de los Santos et al., 2001). Así mismo, géneros de enterobacterias diazotróficas, particularmente en rizósfera de arroz tales como Klebsiella spp, Enterobacter spp, Citrobacter spp, y Pseudomonas spp. (Kennedy, 2004 por Castilla et al., 2006), los cuales podrían estar presentes también en el medio de cultivo estudiado, aportando un mayor número de población en todas las zonas. Lo anterior, permite demostrar además, que la población microbiana más alta se encontró en todas las zonas en este medio de cultivo JMV, descrito por Baldani et al. (1996), donde puede aislarse bacterias del género Burkholderia, el cual comprende 29 especies capaces de fijar nitrógeno en la rizósfera o como endófito (Kennedy, 2004 por Castilla et al., 2006).

Efecto del período de uso del suelo sobre la población de rizobacterias. El tiempo de uso del suelo con cultivo de arroz presentó diferencias significativas en medios $\mathrm{NFb}$ y SRSM. En los medios JMV y Ashby no se encontraron diferencias significativas. En general, los suelos estudiados con más de 10 años de cultivo de arroz y suelos no rizosféricos, no cultivados con arroz, se encontró el menor número de microorganismos en todos los medios utilizados (Tabla 2). En los suelos cultivados durante menos de dos años durante 2 a 10 años, se encontró la mayor población microbiana, especialmente en los medios de cultivo NFb y JMV. Diciembre 2009 ISSN 0122-820X

La mayorpoblacióndefosfatosolubilizadores se presentó en la zona de Restauración en suelos cultivados por más de diez años. Esto

Tabla 2. Número de células de rizobacterias en medio Nfb, JMV, Asbhy y SRSM en suelos cultivados y no cultivados con arroz con respecto al tiempo de cultivo.

\begin{tabular}{|c|c|c|c|c|}
\hline Tiempo de cultivo & $\begin{array}{c}\text { Nfb } \\
{ }^{(1)} \text { Núm. células } \\
g^{1}\end{array}$ & $\begin{array}{c}\text { JMV } \\
{ }^{(1)} \text { Núm. Gélulas } \\
\text { g }^{-}\end{array}$ & $\begin{array}{l}\text { Ashby - } \\
\text { (1) UFC. g }\end{array}$ & $\underset{g^{1}}{\text { SRSM }_{-1)}^{(1)} \text { UFC. }}$ \\
\hline $\begin{array}{l}\text { Suelos no rizosféricos no inter. con } \\
\text { arroz. }\end{array}$ & $4,926 \mathrm{a}$ & $6,404 a$ & $3,823 \mathrm{a}$ & $2,641 \mathrm{a}$ \\
\hline Suelos cultivados menos de 2 años. & $6,076 \mathrm{~b}$ & $6,412 \mathrm{a}$ & $4,015 \mathrm{a}$ & $3,432 a b$ \\
\hline Suelos cultivados de 2 a 10 años. & $5,964 \mathrm{~b}$ & $6,762 \mathrm{a}$ & $3,683 \mathrm{a}$ & $4,054 \mathrm{~b}$ \\
\hline $\begin{array}{c}\text { Suelos cultivados durante más de } 10 \\
\text { años. }\end{array}$ & $5,808 a b$ & $6,947 \mathrm{a}$ & $3,648 \mathrm{a}$ & $3,511 a b$ \\
\hline
\end{tabular}

(1) Análisis estadísticos con datos transformados en Log. Medias seguidas con la misma letra en cada medio evaluado no presentan diferencia significativa entre sí por el Test de Duncan $(\mathrm{P} \leq 0,05)$. 
podría indicar el rol que juegan las poblaciones de microorganismos disolventes de fosfatos en los cultivos de arroz, donde se aplican fertilizantes, especialmente fosforados, lo cual promueve la actividad de este grupo funcional a nivel de la rizósfera. Estos microorganismos liberan en los microhábitats del suelo, iones de fósforo en forma de mono o difosfato a partir de fuentes endógenas de fósforo, en primer lugar, y posteriormente a partir de fuentes exógenas como la roca fosfórica (Vásquez, 2000), con lo cual mantienen un suministro constante de fósforo a las raíces de las plantas. Las plantas a su vez secretan diversos compuestos que los microorganismos utilizan para su multiplicación, permitiendo el aumento de su población en la zona rizosférica, donde se encontró un mayor número de microorganismos en el medio SRSM en todos los suelos con presencia de raíces, difiriendo estadísticamente de suelos no rizosféricos, no cultivados con arroz.

$\mathrm{Al}$ igual que ocurre para la poblaciones diazotróficas, la rizósfera es la zona del suelo donde existe un mayor número de microorganismos solubilizadores de fosfato, puesto que los exudados radicales y detritus vegetal promueven el sustrato energético para que sea posible su actividad solubilizadora (Castilla et al., 2006).

Por otro lado, no se encontraron diferencias significativas con respecto al tiempo de cultivo para rizobacterias endófitas en medio JMV, sin embargo la mayor población se presentó en suelos cultivados de dos a diez años similares a la población presentada en suelos cultivados mayores a diez años. En este medio de cultivo pueden estudiarse microorganismos del género Burkholderia, Sphingomonas y Pseudomonas (Baldani et al., 1996) y seguramente por su diversidad de especies en cada uno de los géneros, se encontró una abundante población en suelos rizosféricos sobre aquéllas muestras provenientes de suelos no rizosféricos, lo cual posiblemente se deba a que los compuestos orgánicos liberados por las raíces tienen una influencia decisiva sobre la disponibilidad de nutrientes y en consecuencia sobre la actividad microbiana (Mengel \& Kirkby, 2000).
Aislamiento de rizobacterias endófitas y asociativas, aeróbicas de vida libre y fosfatosolubilizadoras. En total se obtuvieron 28 aislamientos de rizobácterias endófitas y asociativas, fijadoras libres de nitrógeno y fosfatosolubilizadoras según sus características macroscópicas en agar Batata, JMV, Ashby y nutritivo en cada una de las zonas de estudio y los diferentes periodos de intervención.

\section{Conclusiones}

La zona de Buena Esperanza presentó la mayor población microbiana con respecto a las otras dos zonas estudiadas cultivadas con arroz en el Distrito de Riego del río Zulia debido a las mejores condiciones de fertilidad que presentan los suelos en esta zona.

En los suelos cultivados durante menos de dos años y durante 2 a 10 años, se encontró la mayor población microbiana, debido al corto tiempo de intervención con cultivo de arroz y al poco deterioro que estos suelos han sufrido, por lo tanto, es probable que un mayor número de poblaciones existentes de microorganismos se encuentren allí contribuyendo a la fertilidad y productividad de éstos suelos.

Los suelos estudiados con más de 10 años de cultivo de arroz y suelos no rizosféricos, no cultivados con arroz, mostraron el menor número de microorganismos en todos los medios utilizados como resultado del excesivo laboreo y aplicación de agrotóxicos, aunado con el monocultivo continuado por periodos prolongados.

Veintiocho aislamientos fueron obtenidos de las muestras de suelo analizadas en las tres zonas y en los diferentes periodos de uso del suelo los cuales podrán ser utilizados en la producción de inoculantes microbianos para su aplicación y evaluación en campo en el cultivo de arroz del departamento Norte de Santander, siendo éste un estudio exploratorio en la región, ya que no se ha determinado aún, el potencial biofertilizante de aislamientos autóctonos. 
Efecto del uso del suelo sobre rizobacterias fosfatosolubizadoras y diazotroficas en el distrito de riego del río Zulia, Norte de Santander (Colombia)

\section{Agradecimientos}

Los investigadores agradecen a la Universidad Francisco de Paula Santander y al Instituto Colombiano Agropecuario, ICA por el apoyo logístico ofrecido en el desarrollo de la investigación.

\section{Bibliografía}

Becking, J. The family Azotobacteriaceae en : Balows, A., Tripper, H., Dworking, M., Harder, W. y Schleider, K. 1991b. The prokaryotes. Springer-Verlag. Disponible en: http://141.1 50.157.117:8080/prokPUB/chaprender/jsp/ showchap.jsp?chapnum $=165$.

Baldani, V.L.D., Baldani, J.I. e Döbereiner, J. 1996. Medios de cultura específicos para o isolamento de bacterías endofíticas que fixam N2 atmosférico. Comunicado Técnico No. 12 CNPAB, 4p.

Blanco, O. J. Características físico-químicas de los suelos de las zonas arroceras del Departamento Norte de Santander y recomendaciones integrales de manejo. Cúcuta: Coagronorte, 1999. 16 pp.

Castilla, 1., Luis. La Biofertilización en el manejo de nutrimientos para la nutrición vegetal. Sociedad Colombiana de la Ciencia del Suelo. Capitulo Tolima. 2006. 7, 8 p.

Döbereiner, J.,Baldani, V. L., e Baldani J. I. Como isolar e identificar bactérias diazotróficas de plantas ñao leguminosas. Brazil, EMBRAPA-SPI, 1995.

Estrada-de los Santos, P., Bustillos-Cristales, R. and Caballero-Mellado, J. 2001. Burkholderia a genus rich in plant-associated nitrogen fixers with wide environmental and geographic distribution. Appl. Environ. Microbiol. 67(6): 2790-2798.

Mengel, K. y Kirby, E.A. Principios de nutrición vegetal. International Potash Institute Base, Switzerland. (2000). 692p. ISBN: 3-906535037.

Sadasivan, L. \& Neyra, C.A. 1987. Cyst production and brown pigment formation in aging cultures of Azospirillum brasilense ATCC 29145. J. Bacteriol. 163: 1670-1677.

Santos, M.T., Sontos, M. T. y Cárdenas, D. M. 2006. Aislamiento e identificación de microorganismos con potencial biofertilizante de suelos arroceros del Distrito de riego del río Zulia, Norte de Santander. Revista Respuestas 11(2): 5-13.

Steenhoudt, O., \& Vanderleyden. Azospirillum, a free-living nitrogen-fixing bacterium closely associated with grasses: genetic, biochemical and ecological aspects. En: FEMS Microbiology Reviews. No, 24. 487-506.

Sundara, R. y Sinha. 1963. Phosphate disolving microorganisms in the soil and rhizosfere. Indian J. Agric. Sci. 33: 272-278.

Vásquez, M., Cesar, S., Azcón, R. and Barea, J.M. 2000. Interactions between arbuscular mycorrhizal fungi and other microbial inoculants (Azospirillum, Pseudomonas, Trichoderma) and their effects on microbial population and enzyme activities in the rizosphere of maize plants. Appl. Soil. Ecol., 15: 261-272. 